\title{
Sensitivity of human granulosa cell tumor cells to epidermal growth factor receptor inhibition
}

\author{
Noora Andersson', Mikko Anttonen ${ }^{1,2}$, Anniina Färkkilä ${ }^{1,2}$, Marjut Pihlajoki', \\ Ralf Bützow ${ }^{3}$, Leila Unkila-Kallio ${ }^{2}$ and Markku Heikinheimo ${ }^{1,4}$ \\ ${ }^{1}$ Children's Hospital, University of Helsinki and Helsinki University Central Hospital, PO Box 20, 00014 \\ University of Helsinki, Finland \\ ${ }^{2}$ Department of Obstetrics and Gynecology, University of Helsinki and Helsinki University Central Hospital, \\ PO Box 140, 00290 Helsinki, Finland \\ ${ }^{3}$ Department of Pathology, Helsinki University Central Hospital, University of Helsinki and HUSlab, \\ Haartmaninkatu 3, 00290 Helsinki, Finland \\ ${ }^{4}$ Department of Pediatrics, Washington University School of Medicine, St Louis Children's Hospital, St Louis, \\ Missouri 63110, USA
}

Correspondence should be addressed to $\mathrm{N}$ Andersson Email noora.andersson@helsinki.fi

\begin{abstract}
Epidermal growth factor receptor (EGFR) is implicated in the progression of many human cancers, but its significance in ovarian granulosa cell tumor (GCT) pathobiology remains poorly understood. We assessed the EGFR gene copy number, surveyed the mRNA and protein expression patterns of EGFR in 90 adult GCTs, and assessed the in vitro sensitivity of GCT cells to EGFR inhibition. Low-level amplification of EGFR gene was observed in five GCTs and highlevel amplification in one sample. EGFR mRNA was robustly expressed in GCTs. Most tumors expressed both unphosphorylated and phosphorylated EGFR protein, but the protein expression did not correlate with clinical parameters, including the risk of recurrence. Smallmolecule EGFR inhibitors reduced the EGF-induced activation of EGFR and its downstream signaling molecules at nanomolar doses, but cell viability was reduced, and caspase-3/7 was activated in GCT cells only at micromolar doses. Based on the present results, EGFR is active and abundantly expressed in the majority of GCTs, but probably has only minor contribution to GCT cell growth. Given the high doses of EGFR inhibitors required to reduce GCT cell viability in vitro, they are not likely to be effective for GCT treatment as single agents; they should rather be tested as part of combination therapies for these malignancies.
\end{abstract}
Key Words
- apoptosis
- cell viability
- epidermal growth factor receptor (EGFR) inhibition
- granulosa cell tumor (GCT)
- ovary

Journal of Molecular Endocrinology (2014) 52, 223-234

\section{Introduction}

Granulosa cell tumors (GCTs) are rare malignancies originating from ovarian sex-cord stromal cells, and they represent $\sim 5 \%$ of all ovarian cancers (Schumer \& Cannistra 2003). Typically, they are hormonally active tumors producing estrogen and inhibin (Unkila-Kallio et al. 2000), and both adult and juvenile subtypes can be identified based on their clinical and histological features
(Merras-Salmio et al. 2002, Schumer \& Cannistra 2003). GCTs grow slowly and may recur even decades after the primary diagnosis. Although tumor stage, size, rupture, mitotic index, and nuclear atypia have been suggested to predict recurrence (reviewed in Pectasides et al. (2008)), as yet, there are no clear-cut prognostic factors available (Miller \& McCluggage 2008).

Published by Bioscientifica Ltd. 
GCTs are thought to arise from actively proliferating granulosa cells of preovulatory ovarian follicles. Similar to these cells, GCT cells express follicle-stimulating hormone receptor, aromatase, and inhibin-subunit genes (Fuller et al. 2002). Gene alterations commonly present in several human malignancies have not been identified in GCTs (King et al. 1996, Jamieson et al. 2004, Bittinger et al. 2009, Jamieson \& Fuller 2012). However, adult GCTs exhibit a highly specific somatic point mutation in the transcription factor FOXL2 gene, which is present in $93-97 \%$ of these tumors (Schrader et al. 2009, Shah et al. 2009, Jamieson et al. 2010, Kim et al. 2010a,b, Al-Agha et al. 2011, Gershon et al. 2011).

Epidermal growth factor receptor (EGFR) family members are important regulators of normal cell differentiation, migration, proliferation, and survival (Jost et al. 2000). In the ovary, EGFR and its ligands (EGF, transforming growth factor $\alpha$ (TGF $\alpha$ ), amphiregulin, epiregulin, $\beta$-cellulin, and heparin-binding EGF (Normanno et al. 2005)) have a fundamental role during ovulation as mediators of luteinizing hormone (LH) action (Park et al. 2004). EGFR is the prototype member of the transmembrane ErbB receptor tyrosine kinase family, consisting of EGFR (ErbB1/HER1), ErbB2 (HER2/neu), ErbB3 (HER3), and ErbB4 (HER4). Ligand-bound receptors form homo- or heterodimers and become phosphorylated. EGFR activates an array of signaling cascades including the Ras/Raf/ERK1/2 and PI3K/AKT pathways promoting cell survival and proliferation (McCubrey et al. 2007). Expression of ErbB receptors is commonly altered in several human malignancies: EGFR overexpression and activating mutations, amplifications, or deletions are common in pancreatic cancer, non-small-cell lung cancer and gynecological cancers including breast, ovarian, and cervical carcinomas (Gullick 1991, Janne 2003). EGFRtargeted therapies, including the use of MABs and small molecule tyrosine kinase inhibitors, are in clinical use to treat lung, colorectal, pancreatic, and head and neck cancers (reviewed by Chong \& Janne (2013)) and have already been tested in phase II clinical trials in the treatment of ovarian cancer (Palayekar \& Herzog 2008), but these therapies have not been applied to the treatment of patients with recurrent and aggressive GCTs.

Total EGFR protein expression in GCT tissue samples and in GCT cell lines, the KGN and COV434, has been demonstrated earlier (Leibl et al. 2006, Nosov et al. 2009, Zhang et al. 2010, Jamieson \& Fuller 2012, Nofech-Mozes et al. 2012, Wang et al. 2012). In primary and recurrent GCTs, EGFR expression localizes to the cell membrane and cytoplasm (Leibl et al. 2006, Nosov et al. 2009,
Nofech-Mozes et al. 2012, Wang et al. 2012) and has been suggested to predict GCT recurrence. In this study, we further analyzed the expression pattern of the phosphorylated, active form of EGFR protein in our GCT tissue microarray. We also analyzed the EGFR mRNA expression level and gene copy number in a collection of fresh GCT tumor samples and a series of 90 paraffin-embedded adult human GCT samples respectively. Finally, we assessed whether the effects of EGFR inhibition by three different small-molecule inhibitors affects GCT cell survival by measuring cell viability and apoptosis. Based on our results, GCT cells show intermediate or low sensitivity to the EGFR-targeted inhibitors used.

\section{Materials and methods}

\section{Human tissue samples}

The ethics committee of Helsinki University Central Hospital and the National Supervisory Authority for Welfare and Health approved this study. Informed patient consent was obtained in connection with GCT primary cell cultures before surgery. We used a GCT tissue microarray of 78 primary and 12 recurrent tumors for silver in situ hybridization and immunohistochemistry (Anttonen et al. 2005). Normal ovarian tissue samples from two pre-menopausal women operated on for cervical cancer were used as controls. Finnish legislation does not require patient consent for the use of normal tissue samples when the donor's clinical data are not connected with the tissue analysis, and the chief of the Helsinki University Central Hospital Pathology Department approved the use of the samples in research. RNA was isolated from frozen tumor tissue from 26 primary and five recurrent tumors as described previously (Farkkila et al. 2011) according to the manufacturer's instructions (Nucleospin RNA/Protein kit, catalog no. 740 933.250, Macherey-Nagel, Düren, Germany) and further purified with RNA purification kit (Nucleospin RNA Clean up kit, catalog no. 740 948.50). RNA integrity was verified using Agilent 2100 Bioanalyzer (Agilent Technologies, Santa Clara, CA, USA).

\section{Silver in situ hybridization and immunohistochemistry}

Silver in situ hybridization of the tumor tissue microarray for $E G F R$ gene copy number was conducted according to the method described in Dietel et al. (2007). The following antibodies against total and phosphorylated EGFR were used for immunohistochemistry: anti-EGFr kit 1:25

Published by Bioscientifica Ltd. 
(28-8763, clone 31G7; Zymed Laboratories, South San Francisco, CA, USA) and anti-phospho-EGFR 1:250 (ab40815 Abcam, Cambridge, UK). The antibody used for unphosphorylated EGFR staining has been validated for diagnostic use, and it does not recognize nuclear EGFR (Lo et al. 2005). Staining with secondary antibody was only used as a negative control. The stained tissue sections were examined using a Leica DM RXA microscope (Leica Microsystems GmbH, Wetzlar, Germany) $20 \times / 0.50$ PH2 and $100 \times / 1.30$ OIL PH3 objectives. Stained sections were photographed using an Olympus DP70 camera and DP-capture software (Olympus, Center Valley, PA, USA). The immunostaining of granulosa cells in normal antral follicles was defined as baseline staining to which the staining of tumor samples was compared. GCT samples were then grouped into low-level (samples showing negative or weak positive staining) or high-level (samples showing baseline or highly positive staining) expression groups. Scoring of the EGFR-SISH and immunohistochemistry staining were performed based on consensus of opinion of two independent researchers, and discrepancies were resolved by joint assessment.

\section{Quantitative real-time PCR}

First-strand cDNA synthesis from extracted RNA was performed according to the manufacturer's instructions from $0.8 \mu \mathrm{g}$ total RNA using SYBR Green RT-PCR reagents and random hexamers (Applied Biosystems). The following primers were used for quantitative real-time PCR: EGFR, forward: 5'-CAACATGTCGATGGACTTCC, reverse: 5'-TGCTGGGCACAGATGA; $\beta$-actin, forward: 5'-CTGACGGCCAGGTCATCAC, reverse: 5'-CAGACAGCACTGTGTTGGC. EGFR mRNA levels were corrected to $\beta$-actin expression. Standard curve method was applied using purified mRNA from an established human GCT cell line (KGN; Nishi et al. 2001) as a standard. All analyses were performed in triplicate with an ABI PRISM 7900 sequence detection system (Life Technologies) according to the manufacturer's instructions.

\section{Cell culture and treatment}

The KGN cell line (a generous gift from Dr Yoshihiro Nishi and Prof. Toshihiko Yanase) originating from an adult recurrent GCT was cultured as described previously in DMEM and Ham's F-12 medium containing 10\% (v/v) fetal bovine serum (Nishi et al. 2001). All KGN cell experiments were performed in cells with passage number 8-12. Primary GCT cell cultures $(n=4)$ were established freshly from tumor tissue obtained straight from the operating theatre following intraoperative GCT diagnosis as described (Kyronlahti et al. 2010). In brief, the fresh tumor tissue was minced mechanically, treated with $0.5 \%$ collagenase (Sigma-Aldrich), and filtered through a $140 \mu \mathrm{m}$ mesh. Single cells were plated in the KGN culture medium for experiments. All primary GCT cells used in the study harbored the c. $402 \mathrm{C}>\mathrm{G}$ mutation in FOXL2 gene. Activation of EGFR and its downstream signaling molecules, ERK1/2 and AKT in response to a 10-min EGF stimulation, was assessed in KGN cells in the presence of increasing doses of EGFR inhibitors ( $1 \mathrm{nM}$ to $10 \mu \mathrm{M})$. Cell viability and apoptotic activity were assayed after 48-h incubation. For these assays, both KGN and primary GCT cells were serum-starved for $24 \mathrm{~h}$ prior to treatment with 0.1\% DMSO, $10 \mathrm{ng} / \mathrm{ml}$ EGF (R\&D Systems, Minneapolis, $\mathrm{MN}, \mathrm{USA}$ ), and $1 \mathrm{nM}$ to $30 \mu \mathrm{M}$ gefitinib (kindly provided by Prof. Sirpa Leppä), erlotinib, or lapatinib (Selleck Chemicals, Houston, TX, USA). All EGFR inhibitors were dissolved in DMSO.

\section{IC50, cell number, proliferation, and apoptosis assays}

Twenty thousand cells were plated on 96-well plates for cell viability and caspase activation assays, and 400000 cells were plated for protein analysis experiments on six-well plates. IC50 values (half maximal inhibitory concentrations) were calculated for the EGFR inhibitors by determining the concentration needed to reduce cell viability or the level of phosphorylated EGFR, ERK1/2, and AKT proteins in western blot. Changes in cell viability were assessed using WST-1 cell proliferation assay as instructed by the manufacturer (Roche Diagnostics $\mathrm{GmbH})$. WST-1 reagent was incubated with the cells for $2 \mathrm{~h}$ before measuring absorbance at 450 and $750 \mathrm{~nm}$ wavelengths. Induction of apoptosis was analyzed by caspase-Glo 3/7 assays (Promega Corporation) and DAPI staining for nuclear morphology as described previously (Kyronlahti et al. 2010). In brief, formalin-fixed cells were incubated with cold methanol, washed with PBS, and incubated for $30 \mathrm{~min}$ at room temperature with $0.4 \mu \mathrm{g} / \mathrm{ml}$ of DAPI in PBS.

\section{Western blotting}

Protein from KGN cells was extracted with the NucleoSpin RNA/Protein kit (Macherey-Nagel) according to the manufacturer's instructions, and $10 \mu \mathrm{g}$ protein was separated by SDS-PAGE and transferred onto PVDF membrane. Nonspecific binding was blocked with $5 \%$ nonfat milk or

Published by Bioscientifica Ltd. 
3\% BSA in Tris-buffered saline with $0.1 \%$ Tween for $1 \mathrm{~h}$. The following antibodies were used: rabbit $\alpha$-EGFR 1:5000 (100-401-149; Rockland Immunochemicals, PA, USA), rabbit $\alpha$-phospho-EGFR 1:10 000 (ab40815, Abcam), rabbit $\alpha$-phospho-AKT 1:1000, and rabbit $\alpha$-AKT 1:1000 (\#9271 and \#4691 respectively, Cell Signaling Technology, Inc., Danvers, MA, USA) rabbit $\alpha$-ACTIVE-MAPK (detecting ERK1/2) proteins 1:5000 (V803A, Promega Corporation), rabbit p44/42 MAPK (ERK1/2) 1:1000 (\#9102, Cell Signaling Technology, Inc.), and goat $\alpha$-actin IgG 1:5000 (sc-1616, Santa Cruz Biotechnology, Inc.). Detection was performed using Bio-Rad Immun-Star WesternC kits (Bio-Rad) according to the manual.

\section{Clinical parameters and statistical analyses}

The scoring results from immunohistochemistry and relative mRNA levels were correlated with the following clinical parameters: tumor type (primary/recurrent), subtype (differentiated/sarcomatoid), size $(<10 \mathrm{~cm} / \geq 10 \mathrm{~cm})$, nuclear atypia (low/high), mitotic index (low/high), menopausal status, and stage (Ia/Ib-III) of primary tumors (Farkkila et al. 2011). Statistical analyses were performed using JMP software (JMP 8.0.2, SAS Institute, Inc.,
Cary, NC, USA) and the analyses carried out were one-way ANOVA followed by the $\chi^{2}$ and Fisher's exact tests, simple regression, and Student's t-test, as appropriate. The results were considered statistically significant when $P<0.05$.

\section{Results}

\section{GCTs express EGFR mRNA and EGFR gene copy number is altered in a subset of tumors}

We first characterized the mRNA expression level of EGFR and EGF, the prototype EGFR ligand, in 31 GCT samples (26 primary and five recurrent cases). Both primary and recurrent tumors expressed EGFR mRNA (Fig. 1). Relative EGFR expression levels in the primary and recurrent tumors ranged from 0.23 to 1.61 (Fig. 1A). There were no significant differences in the EGFR mRNA expression levels between primary and recurrent GCTs. All EGFR ligands are expressed only at low levels in GCTs; of these, $\beta$-cellulin, $\mathrm{TGF} \alpha$, and HB-EGF are the most abundant (Benayoun et al. 2012); on-line Array Express repository under accession number E-MTAB-483). We next analyzed the EGFR gene copy number in the GCT tissue microarray
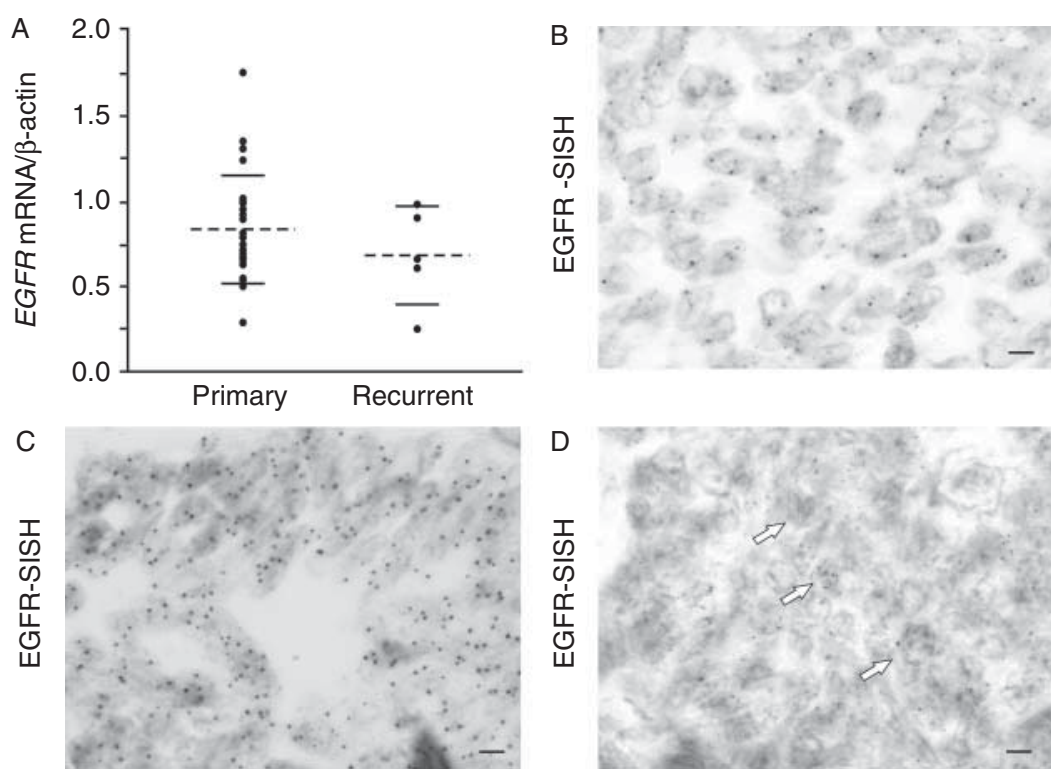

\section{Figure 1}

Relative mRNA expression pattern of EGFR in fresh GCT samples and EGFR-silver in situ hybridization. (A) EGFR mRNA levels are corrected to $\beta$-actin expression. Quantitative PCR was performed on the mRNA isolated from 26 primary and five recurrent GCTs. Dots represent individual measurements, the dotted line shows the mean value and shorter lines represent S.D. (B, C, and D) EGFR gene copy number was analyzed in

83 paraffin-embedded GCT samples. (B) The majority of tumors displayed normal EGFR gene copy number. (C) Low-level amplification was found in five GCT samples and (D) high-level amplification in one GCT. White arrows indicate nuclei with multiple hybridization signals. Original magnification in the large figures is $\times 100$ and the scale bar represents $10 \mu \mathrm{m}$. 
using silver in situ hybridization. Hybridization signal was interpretable in 83 of the 90 GCT samples (73 primary and ten recurrent). Normal gene copy number was found in the majority of the samples (77 samples, 93\%). Low-level EGFR gene amplification (three to five signals/nucleus) was detected in five primary GCT samples $(7.5 \%)$, while high-level amplification (five to ten signals/nucleus) was found in one primary GCT sample from a premenopausal patient diagnosed at the age of 34 years with a small $(<5 \mathrm{~cm})$, well-differentiated stage Ia tumor of low mitotic index and nuclear atypia.

\section{GCTs express activated EGFR protein}

The expression levels of both total and phosphorylated forms of EGFR were assessed by immunohistochemistry in the GCT tissue microarray and in sections of normal human ovary. No immunostaining was detected with secondary antibody only (data not shown). Based on the total and phosphorylated EGFR staining patterns, the tumors were grouped into high- and low-level expressing groups. Positive staining was found in $98 \%$ of all GCTs with both antibodies; high-level total EGFR expression was detected in 40 (44\%) and high-level phosphorylated EGFR in 35 (39\%) of all samples; two samples were negative for total EGFR staining and two samples were negative for phosphorylated EGFR staining (Table 1). Total EGFR expression was localized to the cell membrane and cytoplasm in both normal granulosa cells and GCTs, whereas normal granulosa cells and 13 (14\%) of GCTs showed strong nuclear phosphorylated EGFR staining (Fig. 2B and F). We did not find significant differences in the total or phosphorylated EGFR expression patterns of primary and recurrent tumors, or correlation with the clinical parameters of the patients (Farkkila et al. 2011). The GCT sample with high-level EGFR copy number also displayed high-level total EGFR protein expression, and four of the five low-level amplified tumors also displayed high-level total EGFR expression. The DNA quality of the formalin-fixed paraffin-embedded GCT samples did not allow verification of copy number variations by qPCR.

\section{EGFR inhibition reduces EGFR phosphorylation and cell viability and activates caspase-3/7 in KGN cells}

Short-term stimulation of EGFR with EGF induced the phosphorylation of the receptor and its downstream signaling molecules ERK1/2 and AKT in KGN cells. This was inhibited dose dependently by gefitinib, erlotinib, and lapatinib: EGFR-targeted small-molecule inhibitors (Fig. 3A, B, and C). Gefitinib (Iressa), and erlotinib (Tarceva) inhibit EGFR activation by binding reversibly to the ATP-binding site of the EGFR tyrosine kinase domain, while lapatinib (Tykerb/Tyverb) is a dual inhibitor of both EGFR and ErbB2/HER2. Already at the $10 \mathrm{nM}$ dose, gefitinib markedly reduced the level of EGFR receptor phosphorylation compared with EGF stimulation alone, while a $3 \mu \mathrm{M}$ dose was needed to reduce the receptor phosphorylation to an undetectable level (Fig. 3A). However, the levels of phosphorylated downstream signaling molecules ERK1/2 and AKT were markedly reduced only at doses of $1 \mu \mathrm{M}$ and $300 \mathrm{nM}$ of gefitinib respectively (Fig. 3A). Similarly, erlotinib and lapatinib reduced the EGF-stimulated EGFR activation markedly at 10 and $100 \mathrm{nM}$ doses respectively (Fig. 3B and C). Compared with gefitinib, erlotinib and lapatinib were less effective in reducing ERK1/2 activity but a marked reduction in phosphorylated AKT levels was observed at lower doses compared with gefitinib (Fig. 3B and C).

To determine the effect of EGFR inhibition on GCT cell viability, we treated KGN cells with gefitinib, erlotinib, and lapatinib with doses ranging from 0.01 to $10 \mu \mathrm{M}$. Gefitinib significantly decreased the viability of KGN cells at doses $>1 \mu \mathrm{M}$ and inhibiting concentration that reduces cell viability by $50 \%$ (IC50) was reached at $8.6 \mu \mathrm{M}$ dose (Fig. 3D). Erlotinib did not significantly reduce cell viability with the doses tested, whereas the $10 \mu \mathrm{M}$ dose of lapatinib reduced the cell viability by $40 \%$ (Fig. 3E and F).

We next analyzed whether EGFR inhibition induces apoptosis in GCT cells. KGN cells were incubated for $48 \mathrm{~h}$ in the presence of gefitinib, erlotinib, and lapatinib with doses ranging from $10 \mathrm{nM}$ to $10 \mu \mathrm{M}$. Gefitinib induced a

Table 1 EGFR and P-EGFR expression levels and nuclear staining patterns in primary and recurrent GCT tumors. Primary tumors $n=78$, recurrent tumors $n=12$

\begin{tabular}{|c|c|c|c|c|c|c|}
\hline & \multicolumn{3}{|c|}{ EGFR } & \multicolumn{3}{|c|}{ P-EGFR } \\
\hline & High & Low & Nuclear & High & Low & Nuclear \\
\hline Primary & $37(47 \%)$ & $41(53 \%)$ & $0 \%$ & $30(38 \%)$ & $48(62 \%)$ & $10(13 \%)$ \\
\hline Recurrent & $3(25 \%)$ & $9(75 \%)$ & $0 \%$ & $5(42 \%)$ & $7(58 \%)$ & $3(25 \%)$ \\
\hline
\end{tabular}



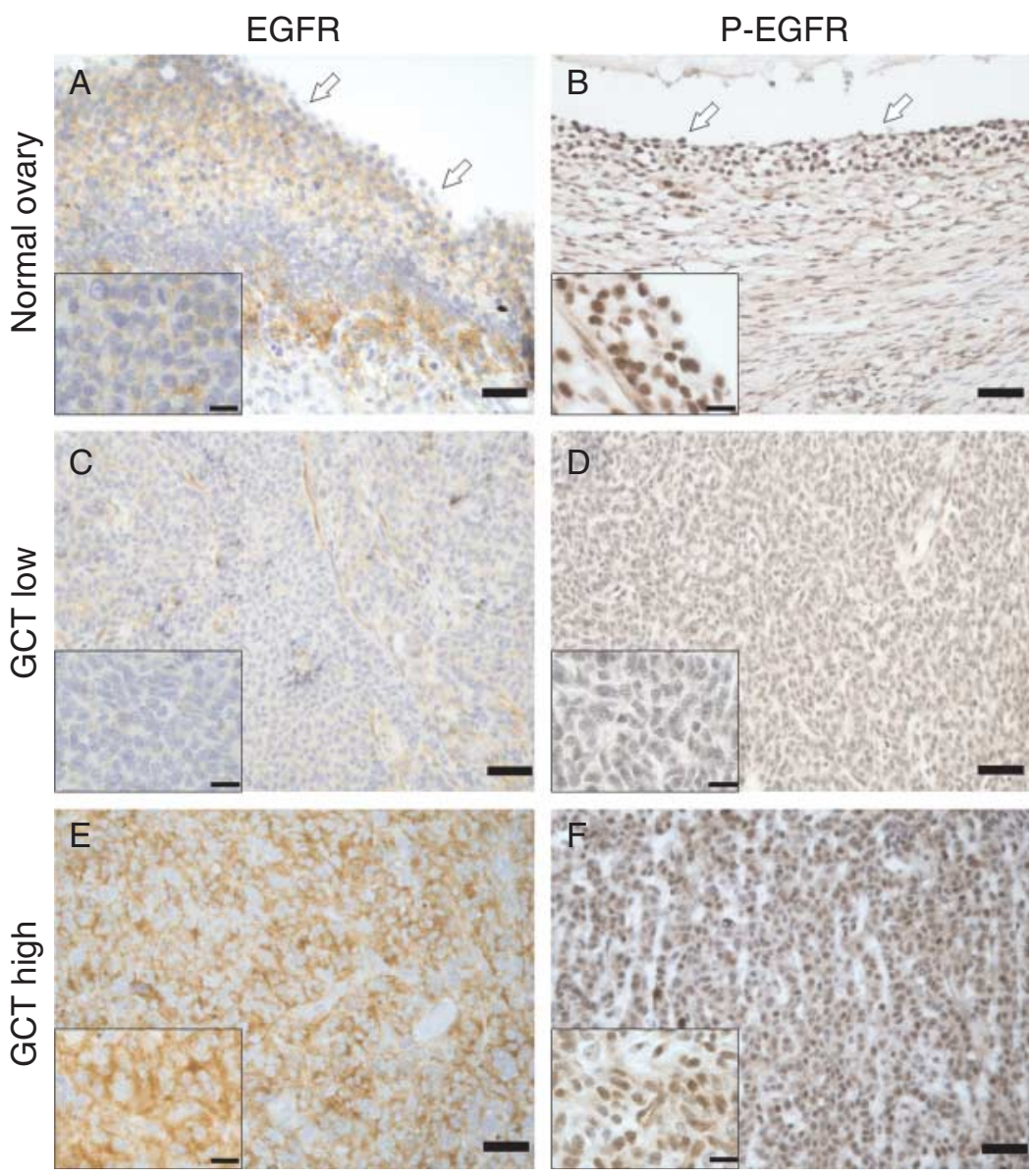

\section{Figure 2}

EGFR expression in normal human antral follicles and granulosa cell tumors. Granulosa cells from large antral follicles express EGFR (A) and phosphorylated EGFR (B). White arrows in (A and B) indicate granulosa cell layers in antral follicles. Higher magnification is represented in insets. Human GCTs showing low-level EGFR and phospho-EGFR expression are

significant increase in caspase-3/7 activity at $1 \mu \mathrm{M}$ and a twofold increase in caspase activity at $3 \mu \mathrm{M}$ dose (Fig. 3G), while both erlotinib and lapatinib induced a significant 1.5 -fold increase in caspase activity even at $10 \mathrm{nM}$ dose (Fig. 3H and I).

\section{High doses of EGFR inhibitors reduce cell viability and induce apoptosis in primary GCT cell cultures}

We also tested EGFR inhibition by gefitinib in primarycultured GCT cells. We measured the cell viability in four primary GCT cell cultures and found that gefitinib reduced the GCT cell viability similar to the findings obtained in KGN cells (Fig. 4A). In the serum-free conditions used, EGF did not affect GCT cell viability. The $10 \mu \mathrm{M}$ dose of gefitinib also induced a significant activation of shown in ( $C$ and $D)$ respectively and high-level expression in ( $E$ and $F$ ) respectively. Original magnification in the large figures is $\times 20$ and the scale bar represents $50 \mu \mathrm{m}$. Magnification in the insets is $\times 100$ and the scale bar represents $10 \mu \mathrm{m}$.

caspase-3/7 in primary GCT cells (Fig. 4B). The number of apoptotic cells was analyzed in DMSO- and gefitinibtreated KGN and primary GCT cell cultures (Fig. 4C). In KGN cells, the percentage of apoptotic cells was doubled by $3 \mu \mathrm{M}$ dose of gefitinib compared with control cells. In primary GCT cells, gefitinib treatment induced a 1.9-fold increase in the number of apoptotic cells compared with control cells at $10 \mu \mathrm{M}$ dose. An image of the nuclear morphology of apoptotic GCT cells is shown in Fig. 4D.

\section{Discussion}

The balance between signals promoting cell survival and death is often disturbed in cancer cells. Growth factors and their receptors together with intracellular signaling molecules mediate extracellular survival signals to normal

Published by Bioscientifica Ltd. 
A

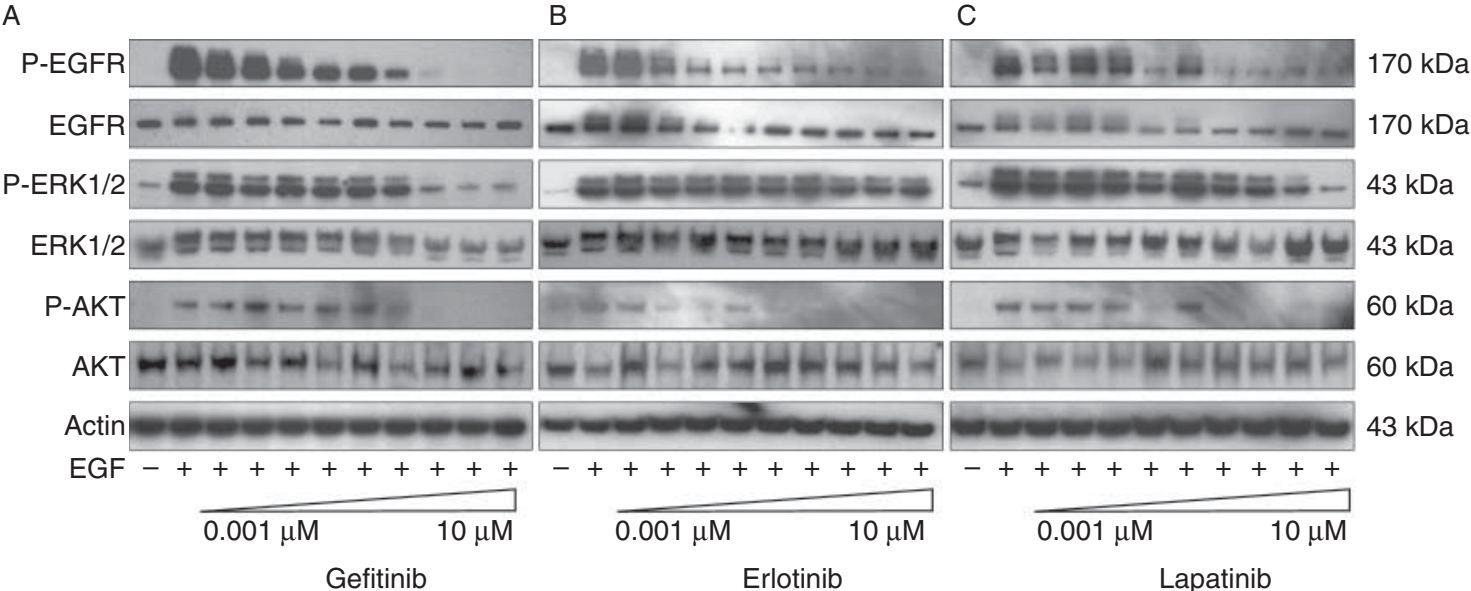

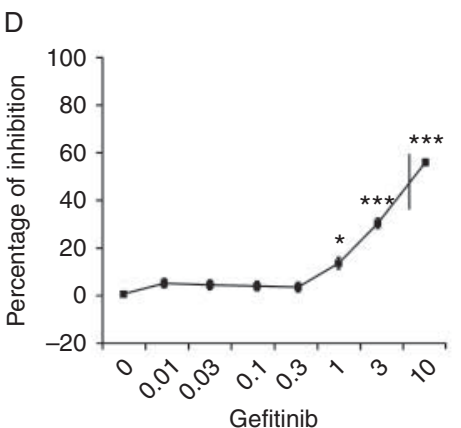

$\mathrm{E}$

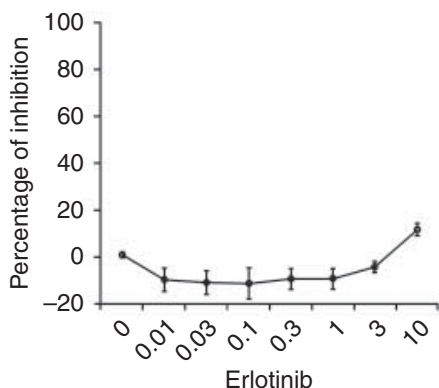

$\mathrm{F}$
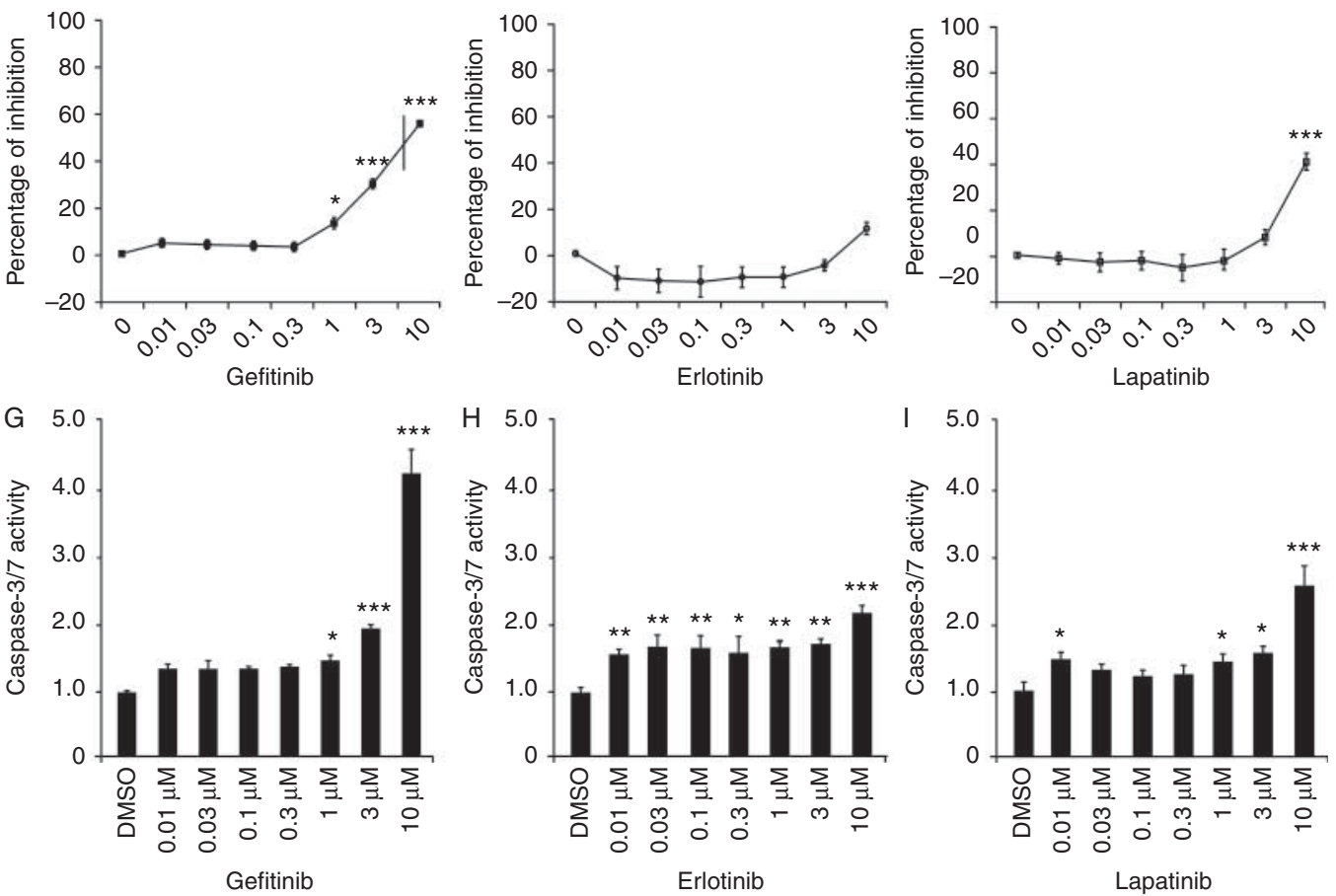

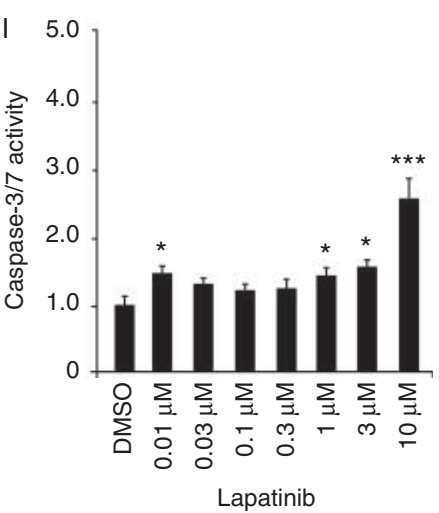

Figure 3

Inhibition of EGFR reduces granulosa cell tumor cell growth. KGN cells were treated either with DMSO or increasing doses of (A) gefitinib, (B) erlotinib, and $(C)$ lapatinib ranging from $1 \mathrm{nM}$ to $10 \mu \mathrm{M}$ for $1 \mathrm{~h}$ and stimulated with $10 \mathrm{ng} / \mathrm{ml} \mathrm{EGF}$ for $10 \mathrm{~min}$. Total protein was extracted and analyzed by western blotting using antibodies against P-EGFR, EGFR, active MAPK (ERK 1/2), total ERK1/2, P-AKT, total AKT, and actin. (D, E, and F) KGN cells were treated with normal growth medium, DMSO, or increasing doses of

cells, and aberrations in these complex signaling networks have been implicated in the progression of cancer. Multiple signaling pathways are likely to be involved in GCT formation and tumor progression, and several transgenic mouse models developing tumors that
(D) gefitinib, (E) erlotinib, and (F) lapatinib, and cell viability was assessed after $48 \mathrm{~h}$ using WST-1 assay. (G, H, and I) Caspase-3/7 activity was measured in KGN cells treated with the $(\mathrm{G})$ gefitinib, $(\mathrm{H})$ erlotinib, and (I) lapatinib after $48 \mathrm{~h}$. Fold changes in caspase activity compared with DMSO control are shown. The data represent the mean \pm s.E.M. of at least three independent experiments ( $\mathrm{A}, \mathrm{B}, \mathrm{C}, \mathrm{G}, \mathrm{H}$, and $\mathrm{I}) .{ }^{*} P<0.05$; ${ }^{* * P}<0.01$; $* * * P<0.0001$ Student's $t$-test.

resemble human GCT have been identified. These include inhibin $\alpha-$, Smad, and $\beta E R$ knockout mouse models as well as $\mathrm{LH}$ overexpressing mice and mice with constitutive activation of Wnt/ $\beta$-catenin (reviewed in Jamieson \& Fuller (2012)). EGFR with its intracellular secondary

Published by Bioscientifica Ltd 

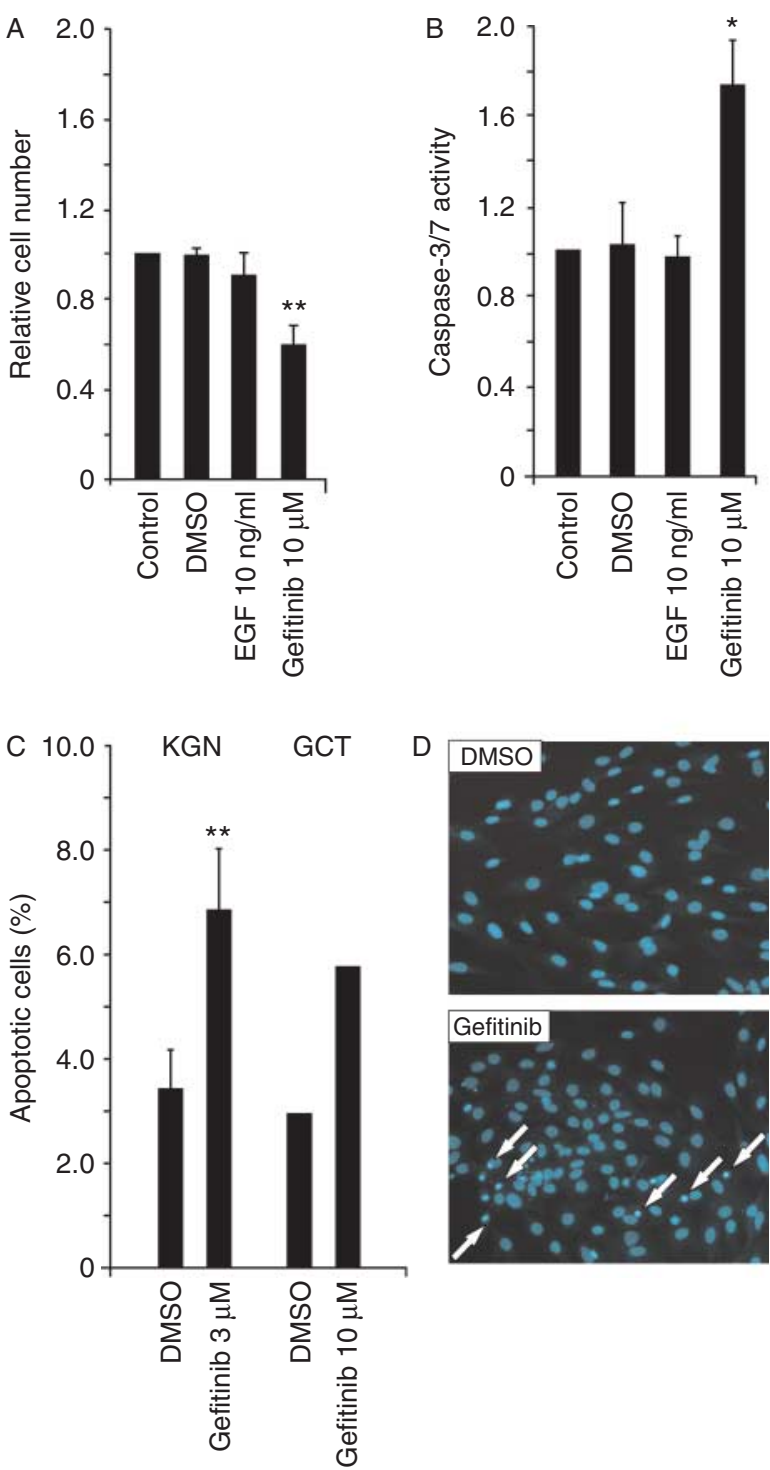

Figure 4

EGFR inhibition reduces cell number and activates caspase-3/7 and apoptosis in ex vivo granulosa cell tumor cells. (A) Changes in cell viability in response to treatment with gefitinib were analyzed by WST-1 in primary GCT cells $(n=4)$. (B) Caspase-3/7 activity was measured in primary-cultured GCT cells after 48-h treatment with either $0.1 \%$ DMSO, $10 \mathrm{ng} / \mathrm{ml}$ EGF, or $10 \mu \mathrm{M}$ gefitinib $(n=3)$. (C) KGN cells and primary GCT cells grown on glass chamber slides were treated with either DMSO or $3 \mu \mathrm{M}(\mathrm{KGN})$ or $10 \mu \mathrm{M}$ (GCT) doses of gefitinib and stained with DAPI. The number of apoptotic cells was counted based on nuclear morphology and is expressed as a percentage of total cell number. (D) The figure shows DMSO- and gefitinibtreated primary-cultured GCT cells from a representative experiment, white arrows indicate apoptotic cells. Data represent the mean \pm s.E.M. of three independent experiments (A and $B$ ). ${ }^{*} P<0.05$; ${ }^{*} P<0.01$; Student's $t$-test.

messengers is among the key regulators of normal cell growth (Henson \& Gibson 2006), and in this study, we investigated the involvement of EGFR and its downstream signaling pathway molecules on GCT cell viability using a GCT cell line and primary human GCT cells.
The molecular phenotype of human GCT cells closely resembles that of actively dividing granulosa cells of preovulatory follicles (Fuller et al. 2002). In the normal ovary, the granulosa cells express EGFR from the primordial follicle stage onward (Prigent et al. 1992, Qu et al. 2000), and during ovulation, LH surge stimulates mural granulosa cells to secrete EGF-like ligands, which subsequently bind to EGFR on cumulus cells surrounding the oocyte. This enables cumulus expansion, oocyte maturation, and ovulation (Park et al. 2004). Similar to normal granulosa cells, EGFR protein is expressed in ovarian GCT cells (King et al. 1996, Leibl et al. 2006, Nosov et al. 2009, Nofech-Mozes et al. 2012, this study). Previously, high total EGFR protein expression has been reported to be prognostic as to GCT recurrence (Nosov et al. 2009), but we did not find correlation between total or phosphorylated EGFR expression and the clinical parameters of the patients in our sample series. Neither did the EGFR mRNA expression levels correlate with the clinical behavior of these tumors. There are several differences between the present and the previously published studies. First, the Nosov et al. (2009) study also included younger patients and juvenile GCTs that exhibit a distinct molecular (e.g. the lack of FOXL2 mutation) and clinicopathological background compared with adult GCTs (Shah et al. 2009, Jamieson et al. 2010, Kim et al. $2010 a, b)$, while this study included only histologically re-evaluated adult GCTs. Secondly, there were also methodological differences in these two studies, such as the use of tissue microarray instead of individual samples and the different scoring methods. All in all, our results obtained in a large series of adult GCTs strongly suggest that EGFR protein expression cannot be used as a prognostic marker for recurrence in these patients.

Alterations in EGFR gene have previously not been reported in GCTs. We here analyzed the EGFR gene copy number in a GCT tissue microarray and found that although the majority of tumors exhibit normal number of signals, six tumors displayed EGFR gene copy number amplification. In colorectal cancer, increased EGFR gene copy number predicts response to anti-EGFR therapy (Algars et al. 2011). Although the low-level EGFR amplification is unlikely to have a major role in GCT pathogenesis, patients with high-level amplification might benefit from EGFR-targeted therapy.

Even though GCTs rarely demonstrate altered gene copy number, it is noteworthy that these tumors commonly express EGFR also in its active phosphorylated form, and thus EGFR may be a potential target for treatment. When activated, EGFR may translocate into

Published by Bioscientifica Ltd 
the nucleus. In this study, total EGFR expression in GCTs was restricted to the cell membrane and cytoplasm, while phosphorylated EGFR localized also into the nucleus in a minority of the tumors. Nuclear ErbB receptors have been suggested to contribute to gene transcription, signal transduction, and tumor progression, as well as DNA repair and replication. Nuclear localization of the ErbB receptors has also been linked to resistance to certain forms of cancer therapy (Wang \& Hung 2009). Furthermore, nuclear EGFR is associated with poor prognosis in several human malignancies including ovarian carcinoma (Xia et al. 2009). In this study, nuclear EGFR localization was not associated with characteristics indicating tumor aggressiveness. It remains, however, unclear that ligand induces the activation of EGFR in the GCTs. The tumors express EGFR ligands only at low levels (Benayoun et al. 2012), and it is therefore possible that the ligand activating the EGFR is not secreted by the tumor cells themselves but rather reaches the tumor cells via the circulation. On the other hand, ligand binding to EGFR could be enhanced in human GCTs analogously to the GCT cells of a SWR mouse strain, in which EGF binding to EGFR was shown to be significantly enhanced compared with normal granulosa cells (Tennent et al. 1989).

It is noteworthy that GCTs also express the other EGFR family receptors, ErbB2/HER2, ErbB3, and ErbB4, and that a ligand toxin HRG/PE40 treatment decreases cell number in another GCT cell model, the COV434 cell line that is thought to represent the juvenile form of GCT (Furger et al. 1998). Amplification or overexpression of HER2 is associated with aggressive disease and poor prognosis in epithelial breast, gastric, and epithelial ovarian cancer (Slamon et al. 1987, Lassus et al. 2004, Tanner et al. 2005), while protein overexpression of HER3 has been reported in non-small-cell lung cancer as well as in breast and ovarian cancers. Also HER4 alterations have been found in breast cancer (Yarden \& Pines 2012). We found that high-level ErbB2/HER2 protein expression in GCTs associates with tumor recurrence and is prognostic for shorter disease-free survival, while ErbB3 and ErbB4 expression did not correlate with the clinical characteristics of GCT patients (Färkkilä et al. 2014).

EGFR-mediated signaling provides cancer cells with increased chances of survival through activating AKT and ERK1/2 pathways (Henson \& Gibson 2006), and biological targeting of EGFR or its downstream signaling molecules using MABs or small molecule inhibitors is already in clinical use for various cancers (Palayekar \& Herzog 2008, Chong \& Janne 2013). ERK1/2 along with the transcription factor NF- $\kappa \mathrm{B}$ that has been linked to EGFR and AKT pathway in breast cancer cells (Biswas et al. 2000) have been shown to be constitutively active in the KGN cell line (Chu et al. 2004, Steinmetz et al. 2004) but have not been investigated in primary GCT cells. We explored here the functional significance of EGFR signaling in GCT cells by inhibiting EGFR function with gefitinib, erlotinib, and lapatinib. All these three inhibitors bind EGFR irreversibly but do not reduce its expression or cause receptor internalization (Dutta \& Maity 2007). EGF stimulation induced the phosphorylation of EGFR and its downstream signaling molecules. The phosphorylation of EGFR was readily reduced at nanomolar doses of the inhibitors, while the phosphorylation levels of AKT and ERK1/2 were markedly reduced only at micromolar doses. These results suggest that even a low amount of activated EGFR is sufficient to induce a marked activation of downstream signaling cascade molecules.

Inhibition of EGFR signaling reduced KGN and primary GCT cell viability with high doses of inhibitors. Similarly, it has previously been shown that AG1478 treatment (another EGFR inhibitor) reduced KGN cell number (Zhang et al. 2010). EGFR inhibitors also induced the activation of caspase-3/7 in GCT cells at similar concentrations as the observed reduction in cell viability, suggesting that the decrease in cell viability is caused by apoptosis. This is in accordance with previous findings in breast cancer cell lines, in which gefitinib also induced apoptosis (Campiglio et al. 2004). In several tumor cell types, gefitinib has been shown to induce apoptosis through inhibition of ERK1/2 and AKT pathways, or via other cell-type-specific mechanisms. Although EGFR activation is readily inhibited by low doses of gefitinib, erlotinib, and lapatinib, effects on downstream signaling molecules and cell survival are only seen at high inhibitor doses, and thus GCT cells show only intermediate or low sensitivity to EGFR inhibition according to the criteria introduced by Noro et al. (2006). Consequently, it is likely that the high doses induce offtarget effects on other tyrosine kinases or signaling pathways that contribute to cell survival.

Despite the marked growth inhibition and induction of apoptosis observed in other cell models in vitro, gefitinib and other EGFR inhibitors as single agents have shown only modest effectiveness in cancer patients in clinical trials (Dutta \& Maity 2007). Glaysher et al. (2013) recently showed that EGFR inhibitors alone exhibited a relatively weak effect on the viability of primary-cultured ovarian cancer cells, while combined treatment with a PI3K inhibitor enhanced the effect. Similarly, GCTs are likely to require a combination of chemotherapeutics for effective treatment. Therefore, a more thorough characterization of

Published by Bioscientifica Ltd. 
the effects of potential therapeutics, also in combination, is needed to improve the treatment of GCT patients.

In summary, we herein show that EGFR gene copy number alterations are rare in GCTs. EGFR mRNA and EGFR protein also in its active, phosphorylated form are abundantly expressed in GCTs, but we could not confirm the previously reported prognostic value of positive total EGFR staining for these tumors. EGFR-targeted inhibitors effectively reduce EGFR activation but have a modest effect on its downstream signaling molecules or cell viability. Our findings suggest that EGFR inhibitors are unlikely to be effective as single agents in this disease but they might serve as additional treatment modalities for GCTs.

\section{Declaration of interest}

The authors declare that there is no conflict of interest that could be perceived as prejudicing the impartiality of the research reported.

\section{Funding}

This work was supported by grants from the Academy of Finland, Helsinki University Central Hospital Research funds, and the Sigrid Jusélius Foundation.

\section{Acknowledgements}

The authors are grateful to Ms Taru Jokinen for her excellent technical assistance and Drs Päivi Miettinen and David B Wilson for critical reading of the manuscript.

\section{References}

Al-Agha OM, Huwait HF, Chow C, Yang W, Senz J, Kalloger SE, Huntsman DG, Young RH \& Gilks CB 2011 FOXL2 is a sensitive and specific marker for sex cord-stromal tumors of the ovary. American Journal of Surgical Pathology 35 484-494. (doi:10.1159/ 000334649)

Algars A, Lintunen M, Carpen O, Ristamaki R \& Sundstrom J 2011 EGFR gene copy number assessment from areas with highest EGFR expression predicts response to anti-EGFR therapy in colorectal cancer. British Journal of Cancer 105 255-262. (doi:10.1016/j.cyto. 2009.01.001)

Anttonen M, Unkila-Kallio L, Leminen A, Butzow R \& Heikinheimo M 2005 High GATA-4 expression associates with aggressive behavior, whereas low anti-Müllerian hormone expression associates with growth potential of ovarian granulosa cell tumors. Journal of Clinical Endocrinology and Metabolism 90 6529-6535. (doi:10.1159/ 000318292)

Benayoun BA, Anttonen M, L'hote D, Bailly-Bechet M, Andersson N, Heikinheimo M \& Veitia RA 2012 Adult ovarian granulosa cell tumor transcriptomics: prevalence of FOXL2 target genes misregulation gives insights into the pathogenic mechanism of the p.Cys134Trp somatic mutation. Oncogene 32 2739-2746. (doi:10.1681/ASN. 2004090742)

Biswas DK, Cruz AP, Gansberger E \& Pardee AB 2000 Epidermal growth factor-induced nuclear factor $\kappa \mathrm{B}$ activation: a major pathway of cell-cycle progression in estrogen-receptor negative breast cancer cells. PNAS 97 8542-8547. (doi:10.1007/s10735-008-9198-6)

Bittinger S, Alexiadis M \& Fuller PJ 2009 Expression status and mutational analysis of the PTEN and P13K subunit genes in ovarian granulosa cell tumors. International Journal of Gynecological Cancer 19 339-342. (doi:10.1002/jcp.22726)

Campiglio M, Locatelli A, Olgiati C, Normanno N, Somenzi G, Vigano L, Fumagalli M, Menard S \& Gianni L 2004 Inhibition of proliferation and induction of apoptosis in breast cancer cells by the epidermal growth factor receptor (EGFR) tyrosine kinase inhibitor ZD1839 ('iressa') is independent of EGFR expression level. Journal of Cellular Physiology 198 259-268. (doi:10.1002/jcp.10411)

Chong CR \& Janne PA 2013 The quest to overcome resistance to EGFRtargeted therapies in cancer. Nature Medicine 19 1389-1400. (doi:10.14310/horm.2002.1345)

Chu S, Nishi Y, Yanase T, Nawata H \& Fuller PJ 2004 Transrepression of estrogen receptor $\beta$ signaling by nuclear factor- $\kappa b$ in ovarian granulosa cells. Molecular Endocrinology 18 1919-1928. (doi:10.1007/s00125004-1597-y)

Dietel M, Ellis IO, Hofler H, Kreipe H, Moch H, Dankof A, Kolble K \& Kristiansen G 2007 Comparison of automated silver enhanced in situ hybridisation (SISH) and fluorescence ISH (FISH) for the validation of HER2 gene status in breast carcinoma according to the guidelines of the American Society of Clinical Oncology and the College of American Pathologists. Virchows Archiv 451 19-25. (doi:10.2337/diabetes.55.02.06 db05-1064)

Dutta PR \& Maity A 2007 Cellular responses to EGFR inhibitors and their relevance to cancer therapy. Cancer Letters 254 165-177. (doi:10.2337/ db09-0204)

Farkkila A, Anttonen M, Pociuviene J, Leminen A, Butzow R, Heikinheimo M \& Unkila-Kallio L 2011 Vascular endothelial growth factor (VEGF) and its receptor VEGFR-2 are highly expressed in ovarian granulosa cell tumors. European Journal of Endocrinology 164 115-122. (doi:10.1152/ajprenal.00137.2012)

Färkkilä A, Andersson N, Bützow R, Leminen A, Heikinheimo M, Anttonen M \& Unkila-Kallio L 2014 HER2 and GATA4 are New Prognostic Factors for Early-Stage Ovarian Granulosa Cell Tumor A Long-term Follow-up study. Cancer Medicine [in press].

Fuller PJ, Chu S, Fikret S \& Burger HG 2002 Molecular pathogenesis of granulosa cell tumours. Molecular and Cellular Endocrinology 191 89-96. (doi:10.1007/s00125-005-1850-z)

Furger C, Fiddes RJ, Quinn DI, Bova RJ, Daly RJ \& Sutherland RL 1998 Granulosa cell tumors express erbB4 and are sensitive to the cytotoxic action of heregulin- $\beta 2 /$ PE40. Cancer Research 58 1773-1778. (doi:10.1507/endocrj.K06-016)

Gershon R, Aviel-Ronen S, Korach J, Daniel-Carmi V, Avivi C, Bar-Ilan D, Barshack I, Meirow D, Ben-Baruch G \& Cohen Y 2011 FOXL2 C402G mutation detection using MALDI-TOF-MS in DNA extracted from Israeli granulosa cell tumors. Gynecologic Oncology 122 580-584. (doi:10.1161/01.HYP.0000078490.59735.6E)

Glaysher S, Bolton LM, Johnson P, Atkey N, Dyson M, Torrance C \& Cree IA 2013 Targeting EGFR and PI3K pathways in ovarian cancer. British Journal of Cancer 109 1786-1794. (doi:10.1097/00004872200410000-00021)

Gullick WJ 1991 Prevalence of aberrant expression of the epidermal growth factor receptor in human cancers. British Medical Bulletin 47 87-98.

Henson ES \& Gibson SB 2006 Surviving cell death through epidermal growth factor (EGF) signal transduction pathways: implications for cancer therapy. Cellular Signalling 18 2089-2097. (doi:10.2337/ db08-1750)

Jamieson S \& Fuller PJ 2012 Molecular pathogenesis of granulosa cell tumors of the ovary. Endocrine Reviews 33 109-144. (doi:10.1111/ j.1440-1797.2008.01047.x)

Jamieson S, Alexiadis M \& Fuller PJ 2004 Expression status and mutational analysis of the ras and B-raf genes in ovarian granulosa cell and 
epithelial tumors. Gynecologic Oncology 95 603-609. (doi:10.1161/ 01.ATV.20.6.1595)

Jamieson S, Butzow R, Andersson N, Alexiadis M, Unkila-Kallio L, Heikinheimo M, Fuller PJ \& Anttonen M 2010 The FOXL2 C134W mutation is characteristic of adult granulosa cell tumors of the ovary. Modern Pathology 23 1477-1485. (doi:10.1530/eje.1.01930)

Janne PA 2003 The role of epidermal growth factor receptor in advanced non-small cell lung carcinoma. Annals of Medicine 35 450-457. (doi:10.1016/j.ejphar.2013.03.024)

Jost M, Kari C \& Rodeck U 2000 The EGF receptor - an essential regulator of multiple epidermal functions. European Journal of Dermatology $\mathbf{1 0}$ 505-510. (doi:10.1038/ki.2012.408)

Kim MS, Hur SY, Yoo NJ \& Lee SH 2010a Mutational analysis of FOXL2 codon 134 in granulosa cell tumour of ovary and other human cancers. Journal of Pathology 221 147-152. (doi:10.1681/ASN. 2006010097)

Kim T, Sung CO, Song SY, Bae DS \& Choi YL 2010b FOXL2 mutation in granulosa-cell tumours of the ovary. Histopathology $\mathbf{5 6} 408-410$. (doi:10.1038/ki.2008.201)

King LA, Okagaki T, Gallup DG, Twiggs LB, Messing MJ \& Carson LF 1996 Mitotic count, nuclear atypia, and immunohistochemical determination of ki-67, c-myc, p21-ras, c-erbB2, and p53 expression in granulosa cell tumors of the ovary: mitotic count and ki-67 are indicators of poor prognosis. Gynecologic Oncology 61 227-232. (doi:10.1016/j.jdiacomp. 2013.06.008)

Kyronlahti A, Kauppinen M, Lind E, Unkila-Kallio L, Butzow R, Klefstrom J, Wilson DB, Anttonen M \& Heikinheimo M 2010 GATA4 protects granulosa cell tumors from TRAIL-induced apoptosis. Endocrine-Related Cancer 17 709-717. (doi:10.3109/00365513.2012.668928)

Lassus H, Leminen A, Vayrynen A, Cheng G, Gustafsson JA, Isola J \& Butzow R 2004 ERBB2 amplification is superior to protein expression status in predicting patient outcome in serous ovarian carcinoma. Gynecologic Oncology 92 31-39. (doi:10.1007/s11255-011-0118-4)

Leibl S, Bodo K, Gogg-Kammerer M, Hrzenjak A, Petru E, Winter R, Denk H \& Moinfar F 2006 Ovarian granulosa cell tumors frequently express EGFR (her-1), her-3, and her-4: an immunohistochemical study. Gynecologic Oncology 101 18-23. (doi:10.5935/0101-2800. 20120007)

Lo HW, Xia W, Wei Y, Ali-Seyed M, Huang SF \& Hung MC 2005 Novel prognostic value of nuclear epidermal growth factor receptor in breast cancer. Cancer Research 65 338-348. (doi:10.1016/S0140-6736 (05)67667-2)

McCubrey JA, Steelman LS, Chappell WH, Abrams SL, Wong EW, Chang F, Lehmann B, Terrian DM, Milella M, Tafuri A et al. 2007 Roles of the raf/MEK/ERK pathway in cell growth, malignant transformation and drug resistance. Biochimica et Biophysica Acta 1773 1263-1284. (doi:10.1159/000345919)

Merras-Salmio L, Vettenranta K, Mottonen M \& Heikinheimo M 2002 Ovarian granulosa cell tumors in childhood. Pediatric Hematology and Oncology 19 145-156. (doi:10.1159/000096870)

Miller K \& McCluggage WG 2008 Prognostic factors in ovarian adult granulosa cell tumour. Journal of Clinical Pathology 61 881-884. (doi:10.1093/cvr/cvp415)

Nishi Y, Yanase T, Mu Y, Oba K, Ichino I, Saito M, Nomura M, Mukasa C, Okabe T, Goto K et al. 2001 Establishment and characterization of a steroidogenic human granulosa-like tumor cell line, KGN, that expresses functional follicle-stimulating hormone receptor. Endocrinology 142 437-445. (doi:10.1016/j.bbrc.2004.02.032)

Nofech-Mozes S, Ismiil N, Dube V, Saad RS, Khalifa MA, Moshkin O \& Ghorab Z 2012 Immunohistochemical characterization of primary and recurrent adult granulosa cell tumors. International Journal of Gynecological Pathology 31 80-90. (doi:10.1152/ajprenal. 00278.2006)

Normanno N, Bianco C, Strizzi L, Mancino M, Maiello MR, De Luca A, Caponigro F \& Salomon DS 2005 The ErbB receptors and their ligands in cancer: an overview. Current Drug Targets 6 243-257. (doi:10.1210/ jc.2003-031916)

Noro R, Gemma A, Kosaihira S, Kokubo Y, Chen M, Seike M, Kataoka K, Matsuda K, Okano T, Minegishi Y et al. 2006 Gefitinib (IRESSA) sensitive lung cancer cell lines show phosphorylation of akt without ligand stimulation. BMC Cancer 6 277. (doi:10.1038/ki.2012.421)

Nosov V, Silva I, Tavassoli F, Adamyan L, Farias-Eisner R \& Schwartz PE 2009 Predictors of recurrence of ovarian granulosa cell tumors. International Journal of Gynecological Cancer 19 628-633. (doi:10.1681/ ASN.2006040331)

Palayekar MJ \& Herzog TJ 2008 The emerging role of epidermal growth factor receptor inhibitors in ovarian cancer. International Journal of Gynecological Cancer 18 879-890. (doi:10.1038/sj.ki.5002516)

Park JY, Su YQ, Ariga M, Law E, Jin SL \& Conti M 2004 EGF-like growth factors as mediators of LH action in the ovulatory follicle. Science $\mathbf{3 0 3}$ 682-684. (doi:10.1258/ebm.2011.010218)

Pectasides D, Pectasides E \& Psyrri A 2008 Granulosa cell tumor of the ovary. Cancer Treatment Reviews 34 1-12. (doi:10.2337/dc10-0739)

Prigent SA, Lemoine NR, Hughes CM, Plowman GD, Selden C \& Gullick WJ 1992 Expression of the c-erbB-3 protein in normal human adult and fetal tissues. Oncogene 7 1273-1278. (doi:10.1111/cen.12041)

Qu J, Nisolle M \& Donnez J 2000 Expression of transforming growth factor- $\alpha$, epidermal growth factor, and epidermal growth factor receptor in follicles of human ovarian tissue before and after cryopreservation. Fertility and Sterility 74 113-121. (doi:10.1161/ ATVBAHA.107.147645)

Schrader KA, Gorbatcheva B, Senz J, Heravi-Moussavi A, Melnyk N, Salamanca C, Maines-Bandiera S, Cooke SL, Leung P, Brenton JD et al. 2009 The specificity of the FOXL2 c.402C > G somatic mutation: a survey of solid tumors. PLOS ONE 4 e7988. (doi:10.2169/internalmedicine.47.0614)

Schumer ST \& Cannistra SA 2003 Granulosa cell tumor of the ovary. Journal of Clinical Oncology 21 1180-1189. (doi:10.1053/j.ajkd.2010.04.013)

Shah SP, Kobel M, Senz J, Morin RD, Clarke BA, Wiegand KC, Leung G, Zayed A, Mehl E, Kalloger SE et al. 2009 Mutation of FOXL2 in granulosa-cell tumors of the ovary. New England Journal of Medicine 360 2719-2729. (doi:10.2337/db05-1174)

Slamon DJ, Clark GM, Wong SG, Levin WJ, Ullrich A \& McGuire WL 1987 Human breast cancer: correlation of relapse and survival with amplification of the HER-2/neu oncogene. Science 235 177-182. (doi:10.5301/jn.5000269)

Steinmetz R, Wagoner HA, Zeng P, Hammond JR, Hannon TS, Meyers JL \& Pescovitz OH 2004 Mechanisms regulating the constitutive activation of the extracellular signal-regulated kinase (ERK) signaling pathway in ovarian cancer and the effect of ribonucleic acid interference for ERK1/2 on cancer cell proliferation. Molecular Endocrinology 18 2570-2582. (doi:10.2337/diabetes.54.5.1607)

Tanner M, Hollmen M, Junttila TT, Kapanen AI, Tommola S, Soini Y, Helin H, Salo J, Joensuu H, Sihvo E et al. 2005 Amplification of HER-2 in gastric carcinoma: association with topoisomerase II $\alpha$ gene amplification, intestinal type, poor prognosis and sensitivity to trastuzumab. Annals of Oncology 16 273-278. (doi:10.1007/s00125-003-1293-3)

Tennent BJ, Beamer WG, Shultz LD \& Adamson ED 1989 Epidermal growth factor receptors in spontaneous ovarian granulosa cell tumors of SWR-derived mice. International Journal of Cancer 44 477-482. (doi:10.1111/j.1523-1755.2005.00601.x)

Unkila-Kallio L, Tiitinen A, Wahlstrom T, Lehtovirta P \& Leminen A 2000 Reproductive features in women developing ovarian granulosa cell tumour at a fertile age. Human Reproduction 15 589-593. (doi:10.1681/ ASN.2012040414)

Wang SC \& Hung MC 2009 Nuclear translocation of the epidermal growth factor receptor family membrane tyrosine kinase receptors. Clinical Cancer Research 15 6484-6489. (doi:10.1210/jc.2005-1117)

Wang C, Lv X, Jiang C, Cordes CM, Fu L, Lele SM \& Davis JS 2012 Transforming growth factor $\alpha$ (TGF $\alpha$ ) regulates granulosa cell tumor 
(GCT) cell proliferation and migration through activation of multiple pathways. PLoS ONE 7 e48299. (doi:10.1371/journal.pone.0048299)

Xia W, Wei Y, Du Y, Liu J, Chang B, Yu YL, Huo LF, Miller S \& Hung MC 2009 Nuclear expression of epidermal growth factor receptor is a novel prognostic value in patients with ovarian cancer. Molecular Carcinogenesis 48 610-617. (doi:10.1111/j.1440-1797.2008. 00949.x)
Yarden Y \& Pines G 2012 The ERBB network: at last, cancer therapy meets systems biology. Nature Reviews. Cancer 12 553-563. (doi:10.1081/ JDI-56597)

Zhang Y, Huang Q, Cheng JC, Nishi Y, Yanase T, Huang HF \& Leung PC 2010 Homeobox A7 increases cell proliferation by up-regulation of epidermal growth factor receptor expression in human granulosa cells. Reproductive Biology and Endocrinology 8 61. (doi:10.1016/j.jhep.2004.12.024)

Received in final form 19 January 2014

Accepted 21 January 2014

Accepted Preprint published online 24 January 2014
Published by Bioscientifica Ltd. 